\title{
Well Testing Analysis of Unconventional Gas Reservoirs: Real Case Study of Tight Gas Carbonate Reservoir, Apollonia Formation, Western Desert, Egypt
}

\author{
Sayed Gomaa ${ }^{1,2 *}$, Attia Attia ${ }^{2}$, Atef Abdelhady², Samir Khaled ${ }^{1,2}$, Mohamed Elwageeh ${ }^{2}$, A.N. El- \\ hoshoudy $^{3}$, Mohamed Omran ${ }^{2}$, Abubakr Essam², Mahmoud Osama ${ }^{2}$, Adel Ashraf ${ }^{2}$, \\ CharlWagdy $^{2}$ \\ ${ }^{I}$ Mining and Petroleum Engineering Department, Faculty of Engineering, Al-Azhar University, Cairo, Egypt. \\ ${ }^{2}$ Department of Petroleum Engineering and Gas Technology, Faculty of Engineering, British University in \\ Egypt. \\ ${ }^{3}$ Production Department, Egyptian Petroleum Research Institute, Cairo, Egypt.
}

*Corresponding Author: Sayed Gomaa, Mining and Petroleum Engineering Department, Faculty of Engineering, Al-Azhar University, Cairo, Egypt.

\begin{abstract}
Unconventional gas reservoirs are basically reservoirs having very low permeability and high anisotropy, which demands particular recovery processes compared to the conventional performing practices. These reservoirs include tight gas, shale gas, and coalbed methane deposits. Production optimization of these reservoirs requires drilling of horizontal wells and applying hydraulic fracturing technique. Well test analysis for unconventional reservoirs is one of the most important methods for analyzing and evaluating these reservoirs. In addition, Gas wells deliverability tests are very important for analyzing the production data of unconventional gas reservoirs. This paper presents the results and analysis of flow after flow test which was conducted on a horizontal well located in tight gas carbonate reservoir in Apollonia formation, Western Desert, Egypt. This reservoir has an original permeability of 0.1md. Horner plot, MDH plot, pressure-difference plot and derivative function were used to analyze the pressure buildup data after performing eight hydraulic fracture stages. The analysis depicts that the permeability and skin factor are improved to $5.5 \mathrm{md}$ and -4.5 respectively. According to the analysis of diagnostic plot, there is a high wellbore storage value of $0.224 \mathrm{bbl} / \mathrm{psi}$ and no skin hump. The analysis of middle time region shows a radial flow; however, the late time region shows a linear flow due the performed eight hydraulic fracture stages. The analysis of deliverability plot depicts that the absolute open flow is $5.5 \mathrm{MMSCF} / \mathrm{D}$ and the production performance coefficient is $0.0014 \mathrm{MSCF} / \mathrm{D} / \mathrm{psia}^{2}$. This work proves the success of the 8 stages hydraulic fracture stimulation job that has been done. In this paper also, a new spread sheet program was developed to perform all required plots and calculations. The results of this program are compared with the results of two commercial softwares (Pansystem and Saphir) and give the same results. The developed spread sheet program accurate, easy to run and not expensive.
\end{abstract}

Keywords: Well Test- Tight Gas- Carbonate Reservoir, Unconventional Pansystem.

\section{INTRODUCTION}

Unconventional reservoirs can add huge amounts of additional energy to our world resources bases like organic shale, tight gas and oil, and coalbed methane. Unconventional gas reservoirs share approximately with one-third of annual natural gas production in USA. In the global scale, unconventional gas reserve scan add 60-250\% to the proven gas reserves (Islam, 2015).

These reservoirs can transform the world global energy market through advances in reservoir characterization, drilling, and completion technologies have turned these reservoirs from uneconomical source rocks into sought-after resources. The greatest industry challenges are the determination of how to systematically convert these unconventional resources potential into economical and commercial proven reserves in the future. The tightening supplies, increased oil demand, emerging recovery technologies, and higher oil prices have stimulated in the investments in unconventional resources all over the world. 
Well Testing Analysis of Unconventional Gas Reservoirs: Real Case Study of Tight Gas Carbonate Reservoir, Apollonia Formation, Western Desert, Egypt

In conventional analysis for unconventional reservoirs, have the highest potential for future energy supply which can be furnishing up to $50 \%$ of the world energy demands. Unconventional resources definition is mainly based on economical restrictions and situations rather than technological restrictions, which are reservoirs with properties that prevent their resources to be recovered at the current economic situation. Their classification bases for unconventional resources to be proven, probable, or possible depends on the basis of the identification, location certainties, in addition to feasibilities, marginal, or sub marginal on the technological feasibility state for extractions and also feasibility of economics. These reservoirs sources are characterized by both of technological and economical risk basis rather than conventional reservoirs. Moreover, unconventional sources can be defined by their difference of intrinsic of their geological sittings, origins, and tapping mechanisms, thus having different methodologies for exploration, production, and development methods.

\section{Case Study OVerview}

This paper presents well test analyses for a real case study of unconventional gas reservoirs. The case study for tight gas carbonate reservoir in Apollonia formation of unconventional gas reservoir which are located in the Western Desert, Egypt. Moreover, this unconventional gas reservoir was being hydraulically fractured for having production stimulation due to very low productivity and permeability.

A new spread sheet and visual basic software programs were developed to perform all required plots and calculations. Fig. 1 presents an interface for PVT estimated data of tight gas case study from URGWTA software. The results of both programs are compared with the results of two commercial softwares (Pan system and Saphir). Both of these developed programs are accurate, easy to run and not expensive.

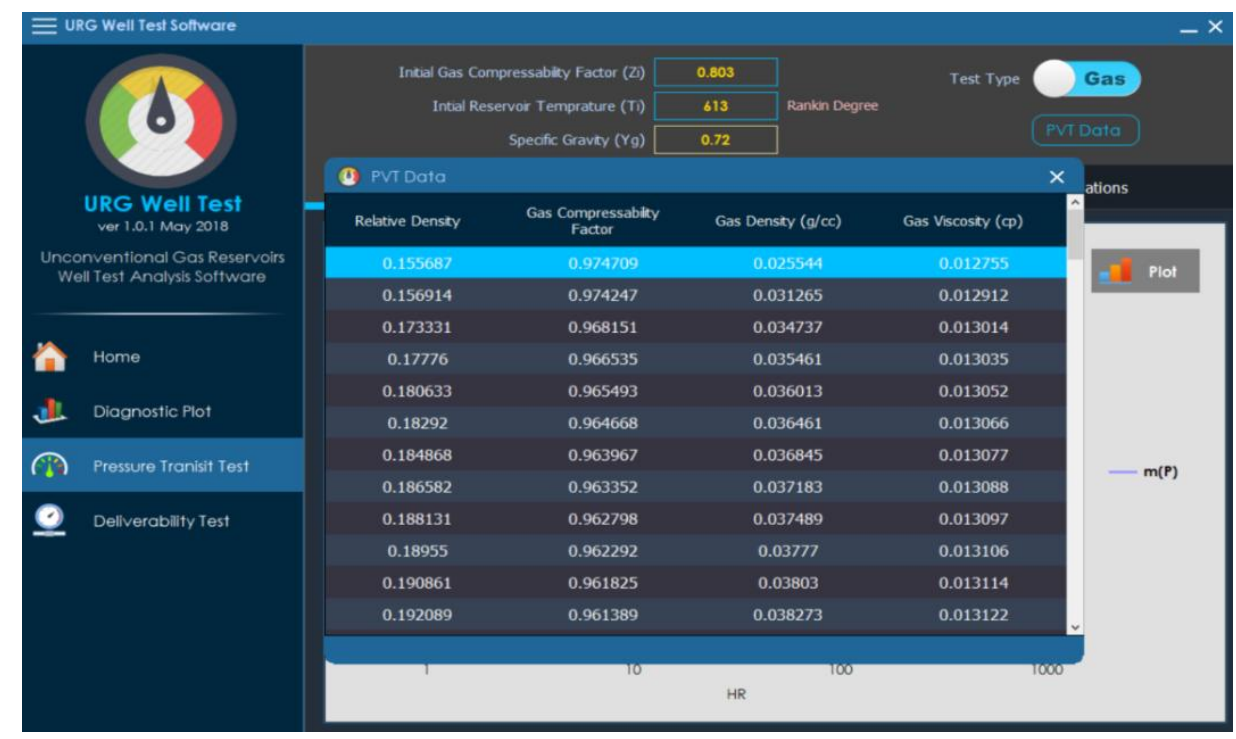

Fig1. PVT estimated data of tight gas case study from URGWTA software.

These programs were conducted depending on some important dry gas correlations and equations as tool for solving any dry gas well test analysis problem. In case of just knowing the specific gravity of the gas without having the PVT data report, this developed spread sheet program can overcome some missing inputs from the PVT data and can get estimations for determining the gas viscosity and gas correction compressibility factor as function of reservoir pressures and reservoir temperature depending on real dry gas equations and iteration methods with high accuracy. Gas compressibility factor, gas viscosity, and real gas pseudo potential pressures considerations, are very important for having well test analysis for dry gas reservoirs which differentiates between black oil and dry gas well test analysis methods.

\section{RESULTS}

The developed spread sheet and visual basic programs were used to analyze the given data of flow after flow test which was conducted on a horizontal well located in tight gas carbonate reservoir in Apollonia formation, Western Desert, Egypt. This reservoir has an original permeability of $0.1 \mathrm{md}$. 
Well Testing Analysis of Unconventional Gas Reservoirs: Real Case Study of Tight Gas Carbonate Reservoir, Apollonia Formation, Western Desert, Egypt

According to the analysis of diagnostic plot as shown in Fig. 2, there is a high wellbore storage value of $0.224 \mathrm{bbl} / \mathrm{psi}$ and no skin hump as shown inside the red circle. The analysis of middle time region shows a radial flow and the analysis of late time region shows a linear flow due the performed eight hydraulic fracture stages.

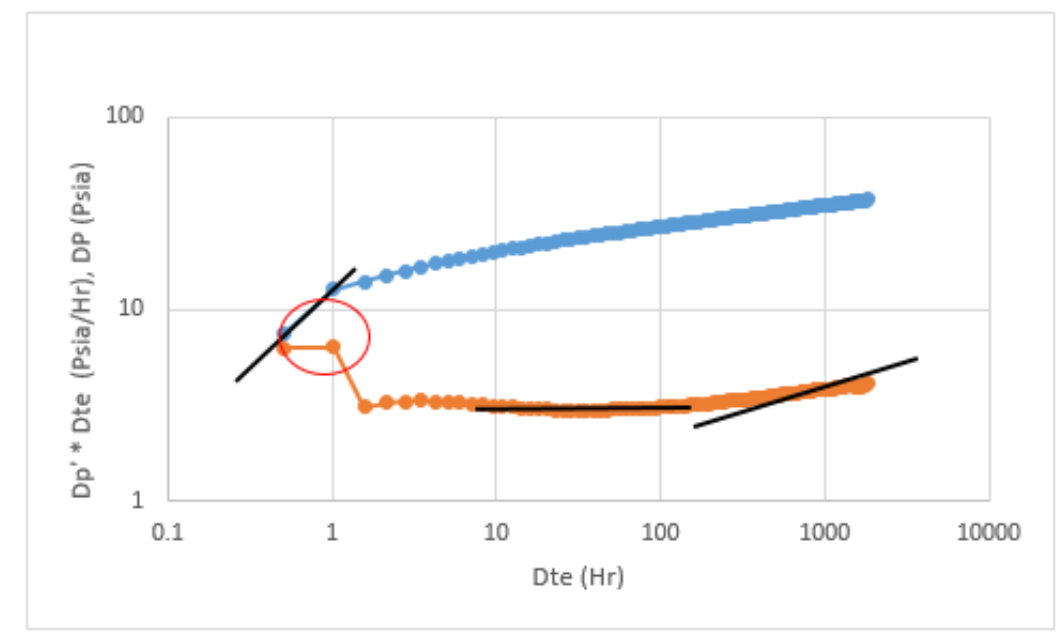

Fig2. Diagnostic plot of tight gas case study from 'Spread Sheet Program

Horner plot, Miller Des Hutchinson plot, pressure-difference plot and derivative function were used to analyze the pressure buildup data after performing eight hydraulic fracture stages. The analysis depicts that the permeability and skin factor are improved to $5.58 \mathrm{md}$ and -4.5 respectively as shown in Fig. 3 and Fig. 4. Moreover, the results of this pressure transient test analysis are shown in Tab. 1.

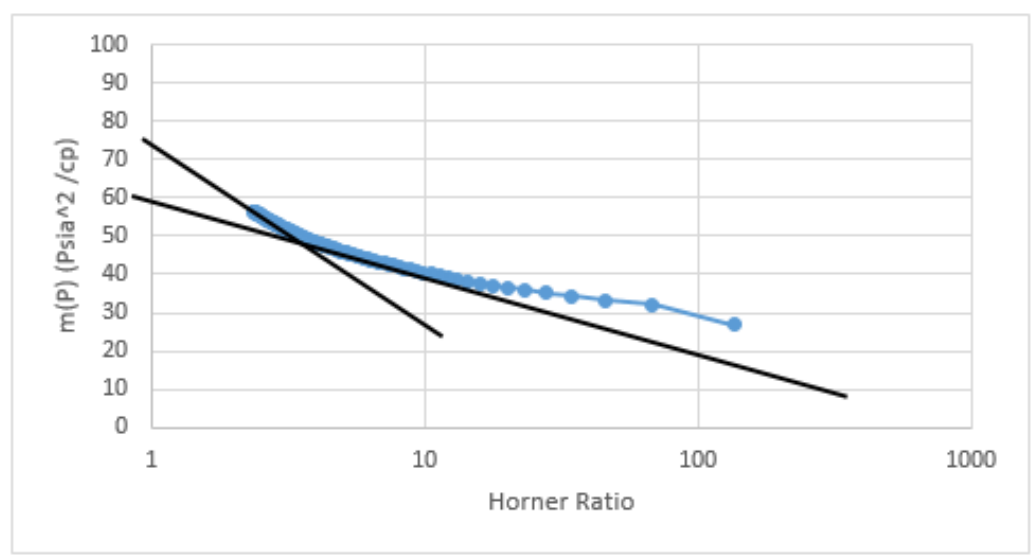

Fig3. Horner ratio plot of tight gas case study from 'Spread Sheet Program

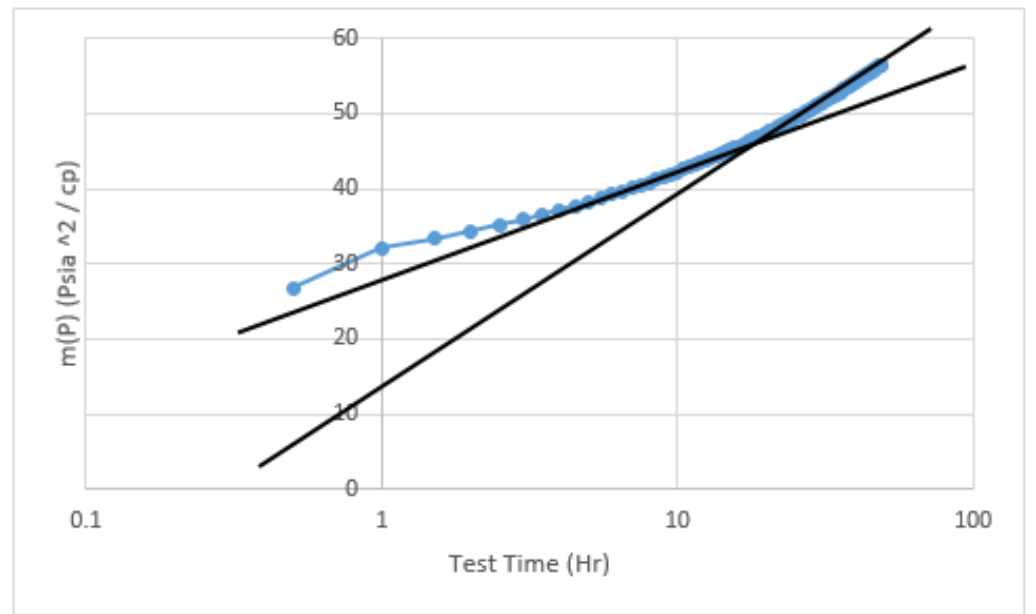

Fig4. Miller Dies Hutchison plot of tight gas case study from 'Spread Sheet Program' 
Well Testing Analysis of Unconventional Gas Reservoirs: Real Case Study of Tight Gas Carbonate Reservoir, Apollonia Formation, Western Desert, Egypt

Table1. Results of the pressure transient test analysis of tight gas case study

\begin{tabular}{|c|c|}
\hline Results of Pressure Transit Test & Values \\
\hline Slope $(\mathrm{m}), \mathrm{psia}^{2} / \mathrm{cp} / \mathrm{cycle}$ & $22 \times 10^{6}$ \\
\hline Permeability $(\mathrm{k}), \mathrm{mD}$ & 5.58 \\
\hline Skin Factor $(\mathrm{s})$ & -4.5 \\
\hline $\begin{array}{c}\text { Additional gas pseudo potential pressure drop } \\
\left(\Delta \mathrm{m}(\text { Pd) }), \mathrm{psia}^{2} / \mathrm{cp}\right.\end{array}$ & $-86.788 \times 10^{6}$ \\
\hline Flow Efficiency, $\%$ & 303 \\
\hline Damage Ratio & 0.329 \\
\hline
\end{tabular}

The analysis of deliverability plot depicts that the absolute open flow is $5.5 \mathrm{MMSCF} / \mathrm{D}$ and the production performance coefficient is $0.0014 \mathrm{MSCF} / \mathrm{D} / \mathrm{psia}^{2}$. By increasing the original permeability from $0.5 \mathrm{mD}$ to $5.58 \mathrm{mD}$, besides decreasing the skin factor to be -4.5 . In addition to increasing the flow efficiency to $303 \%$ is producing of the rate it would have been producing if the well was not damaged. The damage ratio is 0.329 of the production rate would be if the well was not damaged. Thus, this work proves the success of the 8 stages hydraulic fracture stimulation job that has been done as shown in Figs5 through 7.

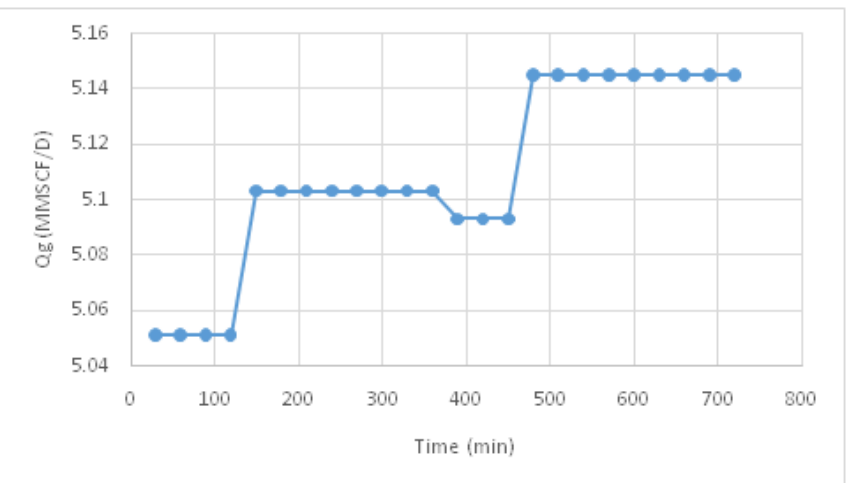

Fig5. Production rate history of tight gas case study from 'Spread Sheet Program'

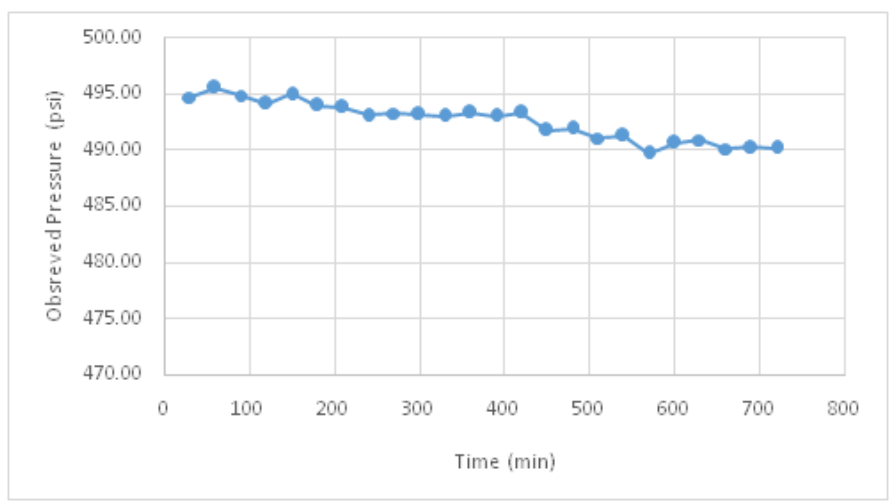

Fig6. Observed pressure history of tight gas case study from 'Spread Sheet Program'

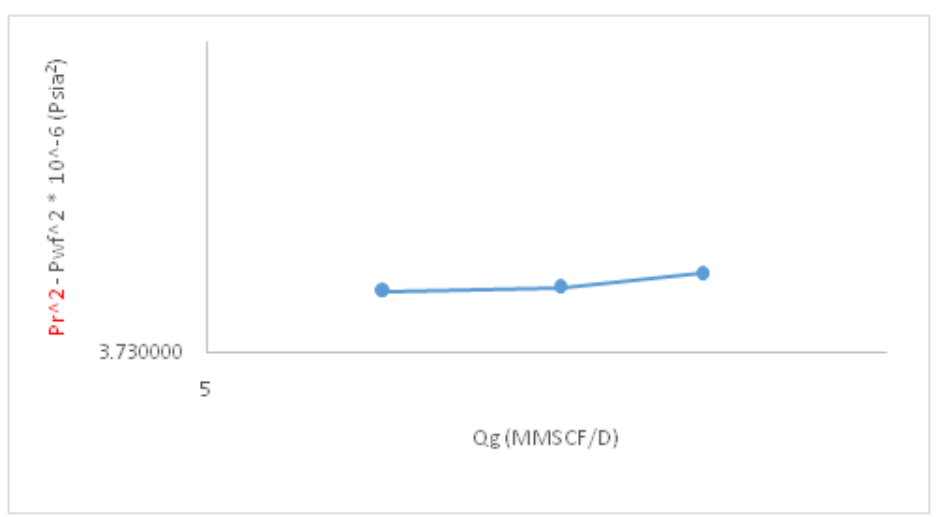

Fig7. Well deliverability test of tight gas case study from 'Spread Sheet Program' 
Well Testing Analysis of Unconventional Gas Reservoirs: Real Case Study of Tight Gas Carbonate Reservoir, Apollonia Formation, Western Desert, Egypt

\section{CONCLUSION}

From this work the following conclusions can be drawn:

- This paper proved that the new spread sheet and visual basic software programs were developed to perform all required plots and calculations.

- The results of both programs are compared with the results of two of well test commercial software's, with high accuracy, easy to run and not expensive.

- Well test analyses for a real case study of unconventional tight gas reservoir were conducted.

- The analysis of diagnostic plot showed that there is a high wellbore storage value of $0.224 \mathrm{bbl} / \mathrm{psi}$ and no skin hump. The analysis of middle time region shows a radial flow and the analysis of late time region shows a linear flow due the performed hydraulic fracture.

- This work proves the success of the hydraulic fracture stimulation job that has been done.

- The analysis of pressure transient test depicts that the permeability and skin factor are improved to $5.58 \mathrm{md}$ and -4.5 respectively. Thus, increasing the flow efficiency to $303 \%$ and decreasing the damage ratio to 0.329 .

- The analysis of deliverability plot depicts that the absolute open flow is 5.5 MMSCF/D and the production performance coefficient is $0.0014 \mathrm{MSCF} / \mathrm{D} / \mathrm{psia}^{2}$.

\section{REFERENCES}

[1] Islam, M. (2015). Unconventional gas reservoirs evaluation, appraisal, and development. $1^{\text {st }}$ edition, Gulf Professional Pub. Elsevier.

[2] Ahmed, T. and McKinney, P. (2005). Advanced reservoir engineering. $1^{\text {st }}$ edition, Gulf Professional Pub. Elsevier.

[3] Ahmed T. and Meehan N. (2011).Advanced Reservoir Management and Engineering handbook. $2^{\text {nd }}$ edition, Amsterdam: Gulf Professional Pub. Elsevier.

[4] Arevalo, J., Ganpule, S. Wattenbarger, R. et. al. (2002). Analysis of Long-Term Performance in Tight Gas Wells: Field Examples. Presented at the SPE International Petroleum Conference and Exhibition, 10-12 February, Villahermosa, Mexico. 74360-MS. https://doi.org/10.2118/74360-MS

[5] Badazhkov, D., Ovsyannikov, D. and Kovalenko, A. (2008), Analysis of production data with elliptical flow regime in tight gas reservoirs. Presented at the SPE Russian oil and gas technical conference and exhibition, 28-30 October, Moscow, Russia. 117023-RU. https://doi.Org /10.2118/117023-RU

[6] Bahrami H. and Siavoshi J. (2013), Presented at the SPE Unconventional Gas Conference and Exhibition, 28-30 January, Muscat, Oman. 164033-MS. https://doi.org/10.2118/164033-MS

[7] Minaein, V., Bahrami, H., Hossain, M., et. al. (2013), Effect of stress anisotropy on well productivity in unconventional gas reservoir. Presented at the SPE Production and Operations Symposium, 23-26 March, Oklahoma City, Oklahoma, USA. 164521-MS. https://doi.org/10.2118/164521-MS

Citation: Sayed Gomaa, et.al (2019). "Well Testing Analysis of Unconventional Gas Reservoirs: Real Case Study of Tight Gas Carbonate Reservoir, Apollonia Formation, Western Desert, Egypt”, International Journal of Petroleum and Petrochemical Engineering (IJPPE), 5(1), pp.1-5, DOI: http://dx.doi.org/ 10.20431/2454-7980.0501001

Copyright: $\odot 2019$ Authors. This is an open-access article distributed under the terms of the Creative Commons Attribution License, which permits unrestricted use, distribution, and reproduction in any medium, provided the original author and source are credited 